Published in final edited form as:

Curr Addict Rep. 2017 December ; 4(4): 439-453. doi:10.1007/s40429-017-0174-7.

\title{
Mechanisms Underlying Sex Differences in Cannabis Use
}

\author{
Katina C. Calakos ${ }^{1}$, Shivani Bhatt ${ }^{1}$, Dawn W. Foster ${ }^{2,3}$, and Kelly P. Cosgrove ${ }^{1,2,4}$ \\ ${ }^{1}$ Department of Neuroscience, Yale University, New Haven, CT \\ ${ }^{2}$ Department of Psychiatry, Yale University, New Haven, CT \\ ${ }^{3}$ School of Public Health, Yale University, New Haven, CT \\ ${ }^{4}$ PET Center, Radiology and Biomedical Imaging, Yale University, New Haven, CT
}

\begin{abstract}
Purpose of the Review-Cannabis is the most commonly used illicit substance worldwide. In recent decades, highly concentrated products have flooded the market, and prevalence rates have increased. Gender differences exist in cannabis use, as men have higher prevalence of both cannabis use and cannabis use disorder (CUD), while women progress more rapidly from first use to CUD. This paper reviews findings from preclinical and human studies examining the sexspecific neurobiological underpinnings of cannabis use and CUD, and associations with psychiatric symptoms.
\end{abstract}

Recent Findings-Sex differences exist in the endocannabinoid system, in cannabis exposure effects on brain structure and function, and in the co-occurrence of cannabis use with symptoms of anxiety, depression and schizophrenia. In female cannabis users, anxiety symptoms correlate with larger amygdala volume and social anxiety disorder symptoms correlate with CUD symptoms. Female cannabis users are reported to be especially vulnerable to earlier onset of schizophrenia, and mixed trends emerge in the correlation of depressive symptoms with cannabis exposure in females and males.

Summary-As prevalence of cannabis use may continue to increase given the shifting policy landscape regarding marijuana laws, understanding the neurobiological mechanisms of cannabis exposure in females and males is key. Examining these mechanisms may help inform future research on sex-specific pharmacological and behavioral interventions for women and men with high-risk cannabis use, comorbid psychiatric disease, and CUD.

\section{Keywords}

Cannabis; Cannabis Use Disorder; Sex Differences; Psychiatric Comorbidity

Corresponding Author: Kelly P. Cosgrove, PhD, Yale University School of Medicine, 2 Church Street South, Suite 511, New Haven, CT 06519, Phone: 203-737-6969, Fax: 203-764-6655, kelly.cosgrove@yale.edu.

Compliance with Ethics Guidelines

Human and Animal Rights and Informed Consent

This article does not contain any studies with human or animal subjects performed by any of the authors.

Conflict of Interest

Katina C. Calakos, Shivani Bhatt, Dawn W. Foster, and Kelly P. Cosgrove declare they have no conflict of interest. 


\section{Introduction}

Cannabis (sativa, indica) is the most commonly used illicit substance worldwide [1]. In the United States, the prevalence of past year cannabis use among individuals aged 12 or older increased from $10.9 \%$ in $2008-2009$ to $13.4 \%$ in 2014-2015 [2]. This increase in prevalence may be due in part to increases in illicit use of cannabis in states with medical marijuana laws [3, 4], as well as decreases in perceptions of risks associated with cannabis [5]. Not only has the prevalence of cannabis use increased, but so too have concentrations of $\Delta^{9}$ tetrahydrocannabinol (THC; the primary psychoactive compound). THC levels in a typical cannabis strain have doubled from 2006 to 2014 [6]. Given the prevalence of cannabis use, the rapidly changing policy landscape, and the proliferation of high-potency products, it is important to investigate the mechanisms underlying cannabis use disorder (CUD), the DSM$\mathrm{V}$ condition characterized by cannabis abuse and dependence.

According to the 2015 National Survey on Drug Use and Health, 2.6\% of adolescents (aged $12-17$ ) and $1.4 \%$ of adults (aged 18+), met DSM-IV criteria for past year cannabis dependence or abuse, though no gender breakdown was noted [7]. For perspective, $2.5 \%$ of adolescents and $6.2 \%$ of adults met criteria for past year alcohol use disorder [7]. In a second national study with gender-specific breakdown of CUD, $2.5 \%$ of adults met DSM-V criteria for past year CUD, with prevalence in men (3.5\%) more than double that in women (1.7\%) [8]. In a sample of adults diagnosed with CUD at some point in their lifetime (i.e., with lifetime CUD), men, relative to women, met a greater number of cannabis abuse criteria [9]. However, in comparison to men, women who use cannabis have been shown to more likely exhibit a "telescoping effect", characterized by faster progression from first use to CUD $[9,10]$. Further, women have reported higher ratings of abuse-related subjective effects in response to cannabis use compared to men [11], which may contribute to a more rapid progression to dependence. Additionally, women with lifetime CUD were more likely than men to have psychiatric comorbidities including bipolar I and II, alcohol use disorder, nicotine dependence, and several externalizing disorders, after adjusting for sociodemographic measures and prevalence of psychiatric disorders [9]. Both the rapid progression from first use to CUD and the increased risk for psychiatric comorbidity conferred by CUD in women implicate biological differences underlying the development and maintenance of CUD. This may render women more vulnerable to psychiatric disability.

The purpose of this review, therefore, is to examine potential neurobiological mechanisms of sex differences in cannabis exposure and dependence. Sex differences in the endocannabinoid system and exogenous THC effects on physiology will be reviewed, followed by sex-specific effects of cannabis exposure during the vulnerable period of adolescence. Preclinical and human studies examining sex differences in cannabis exposure effects during adulthood will then be reviewed, followed by sex differences in cannabis use comorbidity with psychiatric symptomatology related to anxiety, depression, and schizophrenia. Overall, the aim of this review is to yield a better understanding of the neurobiological sex differences that may underlie sex-specific vulnerabilities to, and features of, cannabis dependence. 


\section{Method}

Using PubMed and Google Scholar, we conducted a literature review of peer-reviewed articles published between January 2010 and April 2017. We used the following search terms in various combinations: "cannab*," "sex," "gender," "THC," "marijuana," "female," "sex differences," "schizophrenia," "depression," and "anxiety." Additional papers are cited to provide context for hypotheses investigated in more recent literature. In accordance with definitions set by the Institute of Medicine, the term "gender" is applied to human studies and the term "sex" is applied to animal studies, as well as joint analyses of preclinical and clinical data, in this review.

\section{Sex Differences in the Endocannabinoid System}

\section{Endocannabinoid system biology}

The neurobiology of the endocannabinoid system has previously been reviewed [12-15]. Commonly used terms are defined in Table 1. Briefly, the cannabinoid-1 receptor (CB1-R) is the primary mediator of cannabinoid signaling in the central nervous system [16, 17], and is accompanied in lower levels by cannabinoid-2 receptors (CB2-R) $[18,19]$. Cannabinoid receptors (CB-Rs) are activated by the endogenous ligands $\mathrm{N}$-arachidonoylethanolamine (AEA) [20] and 2-arachidonoylglycerol (2-AG) [21-23], as well as exogenous ligands including THC and synthetic cannabinoids [24]. CB1-Rs are widely distributed in brain regions including frontal cortex, hippocampus, cerebellum, hypothalamus, basal ganglia, and reward circuit areas such as ventral tegmental area and nucleus accumbens [14]. CB1-Rs are presynaptic terminal bound G-protein coupled receptors (GPCRs) that, when activated, trigger $\mathrm{G}_{\mathrm{i} / \mathrm{O}}$-protein coupling and intracellular events that ultimately reduce intracellular $\mathrm{Ca}^{2+}$ and $\mathrm{K}^{+}$concentration and inhibit neurotransmitter release [14]. THC has been shown to induce dopamine release in nucleus accumbens $[25,26]$, which is thought to underlie the rewarding effects of most drugs of abuse [27]. In addition, cannabinoids are shown to decrease GABA-mediated inhibitory transmission [28], modulate NMDA and AMPA receptor mediated excitatory transmission [29], and exert reinforcing effects via CB1-R activation in reward areas mediated by cholinergic and opioidergic systems [30].

\section{Sex differences in cannabinoid receptor expression}

The relationship of sex and the cannabinoid receptor system has long been studied [31-33]. CB1-R mRNA transcript levels have been reported to be higher in anterior pituitary [34] and lower in cerebellum [35], prefrontal cortex, amygdala, and hippocampus [36] in males, compared to females. Greater CB1-R density has been observed in male animals in mesencephalon [37], hypothalamus [38], hippocampus [38, 39], and prefrontal cortex [40], compared to females, with mixed results in amygdala [38, 40], though other evidence suggests greater widespread CB1-R density in females, compared to males [41]. In humans, in vivo positron emission tomography (PET) imaging demonstrated that CB1-R availability is lower in healthy men compared to healthy women in most regions [42, 43], though some evidence indicates higher CB1-R availability in men, compared to women, in the corticostriatal-thalamic-cortical circuit [44]. Conflicting evidence may, in part, be attributed to differences in experimental design, specifically in CB1-R-specific radioligand as well as 
outcome measure. Interestingly, CB1-R availability has been shown to increase with age in women, but not men, in basal ganglia, limbic regions, lateral temporal cortex, and hippocampus [44]. Hormones appear to play a role in these differences since ovariectomized female rats exhibit higher CB1-R expression in frontal cortex [40] and hippocampus [38] compared to intact females, though mixed trends emerge in the amygdala [38, 40]. Sex differences here, and throughout the remainder of this review, with a focus on neurobiological changes in striatum, hippocampus, amygdala, and frontal cortex, are reported in Table 2.

\section{Sex differences in cannabinoid physiological effects and metabolism}

Prior to examining sex differences in cannabis exposure-related behavioral, structural, and functional phenomena, it is important to understand how cannabinoids sex-specifically impact physiology. In humans, cannabis exposure increases heart rate in both women and men [45, 46], but to a lesser extent in women [46-48]. Women have reported greater sedative effects [46] and dizziness [49] compared to men in response to cannabis, though amount of cannabis per body weight was not adjusted. Women also responded to cannabis extract with significantly greater fatigue, drowsiness, and psychomotor suppression compared to women treated with placebo [50].

These sex-dependent physiological effects may, in part, be attributed to sex differences in cannabinoid metabolism. In one study, THC metabolism in female rats yielded the primary metabolite 11-OH-THC only, compared to multiple metabolites in males [51]. Brain levels of metabolite 11-OH-THC were higher in THC-exposed female rats compared to male rats [52, 53], yet plasma THC levels have been shown to be both higher [54] and lower [55] in THC-exposed women, compared to men. This is important, as the typical THC content in cannabis continues to increase over time [6], and may contribute to sex-specific trajectories to dependence. Together, these differences suggest women may experience more depressivelike symptoms from cannabis exposure, including sedation and psychomotor suppression, which may help inform the following findings on sex differences in cannabis use related behaviors.

\section{Adolescent Cannabinoid Exposure Impacts Adulthood: Preclinical Studies}

Cannabis use is typically initiated in adolescence [9], a period marked by robust behavioral and brain development. Cannabinoid use in adolescence has profound effects on cannabis use and related changes in biology and behavior in adulthood [56, 57], in a sex-dependent manner [58-60]. The majority of the literature examining these effects at the neurobiological level is in animal models, with some investigation in humans.

\section{Adolescent cannabinoid exposure has sex specific effects on CB1-Rs in adulthood}

Preclinical cannabinoid exposure in adolescence largely induces a sex-independent, widespread reduction in CB1-R density [41, 61-63], although enhancement in hippocampus in female animals [64-66], and striatum in both sexes [64], has been observed. Chronic THC exposure during adolescence led to a reduction in CB1-R density in the amygdala [61], caudate, putamen, nucleus accumbens, and substantia nigra [41] of adult male rats. In THC- 
exposed female rats, reductions were also observed in these regions, as well as ventral tegmental area [41, 61] prefrontal cortex, globus pallidus, and hypothalamus [41]. CB1-R reduction was observed in hippocampus in females and males, though in more hippocampal sub-regions in females [63]. Additionally, THC exposure reduces striatal CB1-R density in female rats, independent of ovarian hormone status [67]. Adolescent THC exposure has been shown to lead to sex-dependent reduction in agonist-induced activation of CB1-Rs in adulthood, specific to hippocampus, in males, and to amygdala and nucleus accumbens, in females [61]. Deficits in cannabinoid signaling in these brain regions, therefore, could impact emotion and reward regulation.

\section{Adolescent cannabinoid exposure has sex specific effects on other receptor systems in adulthood}

Cannabinoid exposure in adolescence impacts the glutamate, GABA and dopaminergic systems in adulthood. In the glutamate system, adult female rats, with cannabinoid exposure in adolescence, showed reduced NMDA receptor density [41, 68] and reduced glutamate release in hippocampus [68], compared to control females. Adult male rats with cannabinoid exposure in adolescence, in contrast, have shown enhanced NMDA subunit GluN2B expression and AMPA subunit expression compared to control males [69]. In the GABAergic system, both sexes have shown elevated GABA release in adulthood, after cannabinoid exposure in adolescence, but female rats specifically show enhanced hippocampal GABA-A receptor expression compared to control females [68]. In the dopaminergic system, adolescent THC exposure enhanced dopamine D1 receptor density in nucleus accumbens of adult male [70] and female animals [41], increased dopamine D2 receptor density in the prefrontal cortex of males [41], and reduced dopamine D2 receptor density in hippocampus of both sexes [70]. In humans, adult cannabis users with onset in adolescence have shown no difference in striatal dopamine D2/D3 receptor availability compared to healthy controls [71, 72], but do show blunted dopamine transmission compared to healthy controls [73]. Sex differences, however, have not been examined in these imaging studies.

\section{Adolescent cannabinoid exposure has sex specific effects on cannabinoid reinforcing efficacy in adulthood}

Preclinical self-administration paradigms can be used to examine the reinforcing efficacy of drugs of abuse by modeling acquisition and maintenance of drug use [74], including cannabinoid use [75, 76]. Male rats that self-administer cannabinoids in adolescence have exhibited faster and more robust self-administration in adulthood compared to controls [77]. They have also shown a blunted cannabinoid-induced dopamine release in the ventral tegmental area and nucleus accumbens, compared to controls, suggesting a long-lasting deficit in the dopaminergic circuitry [77]. One limitation, however, is that no similar study has been conducted in females to allow for exploration of sex differences. In all, further investigation into female-specific, adolescent cannabinoid exposure effects on THC selfadministration and reinforcing efficacy in adulthood is needed. 


\section{Adolescent Cannabis Exposure Effects on Adolescence and Adulthood: Human Studies}

Similar to preclinical studies, several human studies reveal adolescent cannabis use effects on the brain [78, 79]. Few, however, include female cannabis users and, in those that do, analyses with gender as a main effect is either unreported or unattainable due to statistical limitations [80-82]. Thus, in contrast to the previous exclusive focus on adolescent cannabis use effects on the adult brain, this section's focus is on studies with analyses of gender differences in adolescent cannabis use effects on brain structure and function during adolescence as well as adulthood.

\section{Gender differences in human adolescent cannabis exposure on brain structure and function in adolescence}

In one study, female cannabis using adolescents had significantly larger right amygdalae compared to female non-users, an effect not observed in males [83]. During late adolescence and young adulthood, both female and male cannabis users had smaller grey matter volumes than non-users in decision making and executive function areas of the brain, i.e., the medial orbitofrontal and inferior parietal cortices [84]. In adolescents with substance use disorder and co-morbid conduct problems, many of whom were cannabis dependent, females had less cortical thickness in parts of the anterior cingulate cortex and medial orbitofrontal cortex compared to female controls [85], with no similar effect observed in males [86]. In a separate set of studies, comparably characterized subjects had significantly less grey matter volume than gender-matched controls in left and right dorsolateral prefrontal cortex, in males [87] and females [88], respectively. Bilateral cerebellum was also smaller in male users compared to male controls, and in female users, less grey matter volume was observed in several additional frontal and parietal regions. Together, this evidence indicates genderspecific differences in adolescent cannabinoid exposure on executive function and decisionmaking areas of the brain, which may inform gender-specific cognitive effects of cannabis as well as optimal treatment strategies for cannabis dependence.

\section{Gender differences in human adolescent cannabinoid exposure on brain structure and function in adulthood}

In one study, a mixed-gender adult population with adolescent-onset ( $<17 \mathrm{yrs})$ cannabis use exhibited less grey matter and more white matter, as a percentage of whole brain volume, compared to young adult-onset users [89]. In a second study, adolescent-onset users $(<16$ yrs) showed greater brain activity, measured by blood-oxygen-level dependent (BOLD) functional magnetic resonance imaging (fMRI), in dorsal striatum in response to cannabis cues, compared to young adult-onset users [90]. Although not gender-linked, this may be driven by the significantly more women comprising the adolescent-onset group, though further analysis is necessary [90]. Independent of gender, smaller orbitofrontal cortex volume at age 12 was associated with early cannabis use, highlighting the role of decisionmaking in drug taking behaviors [91]. These findings suggest that regardless of gender, cannabis use leads to a reduction in brain volume in adulthood, which may render early 
cannabis users vulnerable to disease in adulthood, as well as deficits in cognition and behavior, though further investigation is needed to evaluate these implications.

\section{Sex Differences in the Rewarding Properties of Cannabinoids}

\section{Preclinical cannabinoid self-administration}

Preclinical cannabinoid self-administration in adulthood is characterized by an inverted Ushape dose-effect curve that has been demonstrated with CB1-R agonists and THC, although some studies report insufficient reinforcement by THC [92-94]. Cannabinoid selfadministration has led to enhanced extracellular dopamine levels in the nucleus accumbens [95-97], and is modulated by CB1-R [93, 97-99], opioidergic [99-103], and adenosine 2A receptor $[104,105]$ antagonism, and by anabolic steroid hormone treatment [106]. Although sex differences in drug self-administration in general have been reported [107], sex differences tend not to emerge in the cannabinoid literature due to largely male samples. Only one group has explored cannabinoid self-administration in females, and significantly faster acquisition, as well as more robust maintenance, was observed in female rats compared to male rats [108]. Sex-dependent differences do emerge irrespective of selfadministration, such as enhanced sensitivity to THC-induced taste avoidance [109] and THC discrimination [110] in female rats, but further investigation must be done to systematically examine preclinical sex differences in cannabinoid reinforcement.

\section{Human cannabinoid self-administration}

A small but growing gender-inclusive literature exists on human studies of cannabinoid selfadministration [111]. One study of a male cannabis using sample found that participants exhibited preference for and choice of active cannabis over placebo [112]. Other work among male cannabis users has demonstrated increased subjective intoxication, heart rate, and "liking" of drug as a function of THC potency in self-administered cannabis [113, 114]. One study including a female cannabis using sample found that participants similarly exhibited increased intoxication and elevated pulse rate after cannabis use [115]. Further, acute cannabis self-administration by females with moderate cannabis use enhanced confusion, vigor, elation, and friendliness, but prolonged self-administration reduced these feelings [115]. Increased cannabis use during the premenstrual phase of the ovulatory cycle has been reported, and was correlated with significantly greater depressive features [116]. However, no consistently significant relationship between menstrual cycle phase and modulation of cannabis self-administration has been observed [116, 117]. Gender-inclusive studies report similar findings, and additionally demonstrate modulation of selfadministration by treatment with oral THC [118, 119], oral cannabidiol [120], and an opioid receptor antagonist [121]. These studies, however, either lack adequate power to test for gender differences, or do not report analyses of gender differences.

\section{Cannabis-induced subjective effects}

Cannabis and THC alone typically increase subjective "high" ratings in both women and men, but studies conflict as to whether gender-dependent differences exist. One study demonstrated a greater increase in cannabis-induced "high" in female cannabis users compared to males [122], yet another study in non-users exposed to cannabis reported 
greater increases in "high" ratings in males compared to females [123]. Conflicting evidence may be due to smoking status differences in the populations of each study, as well as differences in THC capsule dosing indicated in each experimental design. Cannabis-induced increases in "good" and "take again" ratings were shown to be enhanced in women compared to men [11], but also shown to be gender-independent [48]. In a female-only study, cannabis exposure increased ratings of confusion among regular and intermittent cannabis users, although this effect was stronger among intermittent users [45]. Other female-only work has demonstrated increased psychiatrist-rated scores of poor affective response and emotional withdrawal in drug-naïve females [50].

\section{Cannabis cue reactivity and cue-induced craving}

Gender differences emerge less in the magnitude of cue reactivity, but more in the underlying neural mechanism. For example, prior work has shown that greater cannabis use in both women and men is associated with greater cannabis cue reactivity [124]. Women, compared to men, exhibited larger cue-induced enhancement of event related potential signals, specifically in P300 amplitude, shown to be enhanced in many studies of drugrelated cue reactivity, and in early posterior negativity amplitude, shown to be sensitive to motivation-related stimuli [124]. In cannabis users exposed to subliminally presented cannabis cues, men had preferential BOLD signal response in left striatum and left lateral orbitofrontal cortex, yet women preferentially responded in striatum, left hippocampus and amygdala [125]. Some groups have examined cue-reactivity associations with risk genes $C N R 1$ and $F A A H$, but gender differences were either not found [126] or not further analyzed [127]. Cannabis cue-induced craving has been reported in both men and women [128]. Further, in a mostly female sample of cannabis users, cue-induced craving was correlated with occipital cortex, parahippocampal gyrus, thalamus, hippocampus, superior temporal pole, and middle occipital gyrus activation [129]; however, within-group gender differences were not reported. In women, cannabis cue-induced neural activation of bilateral anterior insula and left lateral orbitofrontal cortex positively and negatively correlated with baseline craving, respectively [125]. In men, striatal activation was associated with craving [125]. Thus, although overlap exists in brain regions associated with cannabis cue presentation between women and men, the correlation of regional activation with cannabis craving is gender-dependent, which may inform optimal treatment strategies aimed at reducing craving and preventing relapse in cannabis-dependent individuals.

\section{Gender Differences in Brain Structure and Function in Cannabis Users in Adulthood}

\section{Gender differences in brain structure}

Several groups have investigated structural brain changes related to cannabis use [130, 131], yet as with the adolescent literature, few studies include women or analyze gender differences, as discussed and reviewed by Ketcherside and colleagues [132]. In mixedgender populations, cannabis users have exhibited more grey matter volume in cerebellum [133], left putamen, and right precentral gyrus [134], and less thalamic [134] grey matter volume compared to healthy controls. Further, smaller volumes in right amygdala and 
bilateral hippocampus were associated with greater cannabis dependence severity and amount of cannabis used per week, respectively [133]. Volume of ventricular cerebrospinal fluid was reported to be lower in cannabis users, compared to controls, without varying by gender [135]. In one recent study, dependent cannabis users, compared to non-dependent users, had significantly smaller volumes in medial and lateral orbitofrontal cortex, the latter effect being more pronounced in women than men [136]. Overall, more structural neuroimaging of gender differences in current cannabis users is needed to elucidate consistent patterns of change in brain structure, specific to female and male cannabis users.

\section{Gender differences in brain function}

Similarly, several functional neuroimaging studies inclusive of women cannabis users lack statistical power or do not report gender differences [71,73,137, 138]. Of those that examine gender differences, mixed results emerge. In an electroencephalogram study, female cannabis users showed altered visual processing as indicated by reduced visual steady state evoked potential spectral power at low frequency stimulation compared to female controls, an effect not observed in males [139]. In adulthood, males who began using cannabis during adolescence had significantly higher cerebral blood flow compared to those who initiated use as young adults, though females showed no significant difference [89]. Female cannabis users did, however, exhibit region-specific lower levels of glucose metabolism in left superior frontal gyrus, right occipital cortex, and right anterior cingulate cortex compared to female controls, an effect not observed in men [140]. Further, female cannabis users, but not male cannabis users, had blunted methylphenidate-induced enhancement of glucose metabolism in cerebellum, medial frontal gyrus, pons, hippocampus, thalamus, and midbrain compared to female controls [140]. In a mixed group of adolescents and young adults, female cannabis users, in dorsal striatum, had lower scaled levels of glutamate and glutamine compared to female controls, an effect not observed in males, as well as higher myo-inositol levels, a glial marker observed in high concentrations in early dementia, compared to female controls and all males [141].

\section{Sex Differences in Cannabis Use Comorbidity with Psychiatric Symptoms Comorbidity with anxiety symptoms}

Female cannabis users have self-reported significantly higher levels of anxiety problems during withdrawal compared to male cannabis users [142]. Females seeking treatment for cannabis dependence, particularly in late adolescence and middle adulthood, have also shown higher rates of anxiety compared to males [143]. Social anxiety disorder symptoms were correlated with cannabis use disorder symptoms in women but not men [144]. This relationship appears to be nuanced, however, by reported motives for cannabis use.

Specifically, social anxiety in males has been associated with cannabis use motives related to conformity (e.g., to fit in with a group I like) and coping (e.g., to forget my worries) [145]. By contrast, in females, social anxiety has been associated with social-based motives (e.g., to enjoy a party) to use cannabis [145]. It is unclear what mechanism may contribute to these differences, although the amygdala has been implicated [83]. Specifically, as detailed earlier, female cannabis users had larger right amygdala volumes compared to female non-users, an effect not observed in males [83]. Further, in female cannabis users, larger right amygdala 
volume was associated with worse anxiety and depression symptomatology, yet the opposite trend was observed in female controls and males [83]. While gender differences have emerged with respect to anxiety symptoms and motives, additional work is needed to elucidate gender differences in mechanisms related to cannabis motives and anxiety.

Preclinical investigation has begun to address this gap by exploring potential mechanistic explanations for sex-dependent associations between cannabinoid exposure and anxiety. Some groups reported no effects of adolescent cannabinoid exposure in rodents on anxiety in adolescence [146] or adulthood [61,69], and others reported a male-specific reduction in anxiety or anxious behavior with cannabinoid exposure [147-149]. Adequate comparison of conflicting results is limited, however, as these studies vary in their administered cannabinoid (i.e., CP 55,940 vs. THC) which may impact potency of effect at the receptor level. Female rats have similarly shown mixed anxiety effects to cannabinoid exposure [150], and cannabinoid-induced enhancement of social anxiety, specifically, has been noted in females [151] and males [147]. CB1-R activity may mediate these effects, as global knockout of this receptor expression increased anxiety in male mice compared to controls, an effect not observed in female mice [152]. Further, specific CB1-R knockout on cortical glutamatergic and forebrain GABAergic neurons was associated with reduction in social interaction in male mice, with no females tested in this experiment [153].

\section{Comorbidity with depressive symptoms}

Evidence for gender-specific associations of depression and cannabis use is mixed. Crosssectional work has indicated a stronger association between cannabis use and depression in females, compared to males [154], but longitudinal work indicates a strong association over time in both females [155] and males [156]. Adolescent cannabis use has been shown to be predictive of depression in male and female adolescent students [157]. Adolescent cannabis use, however, did not significantly predict young adult depression [158]. Studies on factors associated with depression have shown that in comparison to males, female cannabis-using adolescents are at greater risk for suicide [143], as well as self-harm as a function of cannabis use [159]. In a longitudinal study, heavy cannabis use in males, but not females, was significantly associated with increased odds of later suicidal ideation [160]. In contrast, past suicidality in females, but not males, was associated with initiation of cannabis use [160]. Another study showed that cannabis craving was correlated with self-reported depression, and when depression was held as a covariate, greater craving scores emerged for males compared to females [161]. Further, cannabis-dependent males in a separate study exhibited greater feelings of "down" in response to cannabis cues compared to females [162], and as previously mentioned, cannabis-naïve females showed increased, cannabisinduced, psychiatrist-rated poor affective response and emotional withdrawal [50]. While the literature is mixed, it seems apparent that gender differences exist, and additional work is needed to understand mechanisms contributing to these patterns.

Aside from the aforementioned evidence for increased anxiety and depression symptomatology with right amygdala volume in female cannabis users [83], we are not aware of further mechanistic understanding of gender differences in cannabis use associated with depression. Investigations in mixed-gender populations have indicated that smaller

Curr Addict Rep. Author manuscript; available in PMC 2018 December 01. 
white matter volume is associated with greater depression symptomatology in adolescent cannabis users [163]. Cannabis users had more cerebellar grey matter volume compared to non-users, but this was not associated with depressive symptoms [133]. Preclinical studies have indicated that adolescent THC exposure elevates depressive-like behavior in adulthood in female rats [61, 164] but not male rats [61]. Cannabinoid exposure in males, in contrast, has been shown to decrease depressive-like behavior [149, 165]. Conflicting evidence does exist, however, as elevated depressive symptoms in both sexes [41], or no effects in males [69], have been reported. Altogether, cannabis use correlates with several measures of depression in humans, cannabinoid exposure has mixed effects on depressive symptoms in preclinical animal models, and varied sex-specific associations between cannabis use and depression emerge across studies, necessitating further inclusion of females in studies of depression in cannabis use.

\section{Comorbidity with schizophrenia and psychotic symptoms}

Cannabis use has been implicated in the onset of schizophrenia and psychotic symptoms [166]. Men have been shown to have an earlier onset of schizophrenia than women [167, 168], and age of onset of in cannabis users is shown to be earlier than non-users [168, 169]. Though cannabis use was shown to be more prevalent among men with schizophrenia relative to women [170], female cannabis users are reported to be at higher risk of early onset of psychosis compared to male users [171]. Possible genetic factors involved in gender-specific differences in age of psychosis onset have been reported [167, 172]. Neuroimaging studies suggest that individuals with schizophrenia who use cannabis have an altered subcortical region shape [173] and have less grey matter in anterior cingulate [174], posterior cingulate cortex [175], and more widespread regions in the brain [176, 177] compared to non-using controls with schizophrenia, though gender difference analysis is not reported or not observed as in one case [174]. In rodents, psychotic-like behavior is modeled by diminished prepulse inhibition, related to deficits in sensorimotor gating and attention in people with schizophrenia, and enhanced acoustic startle reflex [178]. THC exposure significantly reduced prepulse inhibition in female rats [178] and enhanced acoustic startle activity in both males and females [179]. These findings highlight potential mechanisms that may contribute to sex differences in the impact of cannabis on schizophrenia and psychosis.

\section{Conclusion}

Cannabis is the most commonly used illicit substance, and as it becomes increasingly accessible, it is critical to understand how the neurobiological underpinnings of cannabis addiction differ between women and men. Sex differences exist in the endogenous cannabinoid receptor system, cannabis metabolism, and the subjective effects of cannabis. There are not yet studies, however, reporting consistent differences in brain structure or function between female and male cannabis users. More commonly, gender differences emerge in how female or male cannabis users compare with their same-gender non-user counterparts. This is evident structurally, with less grey matter volume and cortical thickness observed, and functionally, with blunted methylphenidate-induced enhancement of glucose metabolism in hippocampus and frontal cortex, in female cannabis users compared to female non-users.

Curr Addict Rep. Author manuscript; available in PMC 2018 December 01. 
Gender differences emerge in behavioral and neurobiological profiles of cannabis users with comorbid symptomatology related to anxiety, depression, and schizophrenia. Social anxiety disorder symptoms correlated with CUD symptoms in women, but not men, and anxiety symptoms correlated with larger amygdala volume in female cannabis users. Female cannabis users are shown to be especially vulnerable to earlier onset of schizophrenia, compared to male cannabis users, but it is unclear what neurobiological sex differences contribute to this phenomenon and more studies are necessary. Lastly, in depression, mixed trends emerge in support of enhanced depressive symptoms with cannabis use in both females and males. Amygdala is again implicated in females, but further investigation is required.

Taken together, the studies reviewed here that examine gender differences in neurobiological mechanisms of cannabis use yield mixed results and thus, more evidence is needed to fully understand how cannabis use differentially impacts females and males. Differences in experimental design of preclinical studies may contribute to conflicting findings, such as differences in cannabinoid used to antagonize the CB1-R system or in paradigms used to evaluate reinforcing efficacy of cannabis. Similarly, differences in neuroimaging parameters, cannabis dosing, and type of cannabis administration in clinical studies may produce competing results obtained to answer the same research question. Further, many studies still do not include female subjects and in those that do, gender is not often discussed as a variable of interest. This makes it difficult to identify promising avenues for investigating gender differences in future research.

In future studies, it is important to actively include female and male subjects, and to systematically examine sex differences, with adequate power, in both preclinical and clinical samples. The majority of clinical studies on gender differences in cannabis use either administer cannabis to assess subjective effects without measures of neural activity or examine neural activity in cannabis users without active cannabis administration. To fully understand gender differences in cannabis use, it is critical that new studies bridge the gap between these two paradigms and incorporate active cannabis administration into neuroimaging studies. Acute effects of cannabis use, both behaviorally and neurobiologically, could then be identified and analyzed for differences between women and men. Examination of sex differences and related neurobiological mechanisms is critical to inform future research on gender-specific pharmacological and behavioral interventions for women and men with high-risk cannabis use, comorbid psychiatric disease, and CUD.

\section{References}

Papers of interest, published in recent years, have been noted as:

- Of importance

1. World Drug Report 2016. United Nations Office on Drugs and Crime.

2. The NSDUH report. U.S. Dept. of Health \& Human Services, Substance Abuse and Mental Health Services Administration, Office of Applied Studies; Rockville, MD: 2015. Comparison of 20082009 and 2014-2015 NSDUH State Prevalence Estimates.

3. Hasin DS, et al. US Adult Illicit Cannabis Use, Cannabis Use Disorder, and Medical Marijuana Laws: 1991-1992 to 2012-2013. JAMA psychiatry. 2017 
4. Martins SS, et al. State-level medical marijuana laws, marijuana use and perceived availability of marijuana among the general US population. Drug and alcohol dependence. 2016; 169:26-32. [PubMed: 27755989]

5. Volkow ND, et al. Adverse health effects of marijuana use. New England Journal of Medicine. 2014; 370(23):2219-2227. [PubMed: 24897085]

6. ElSohly MA, et al. Changes in Cannabis Potency Over the Last 2 Decades (1995-2014): Analysis of Current Data in the United States. Biological Psychiatry. 2016; 79(7):613-619. [PubMed: 26903403]

7. The NSDUH report. U.S. Dept. of Health \& Human Services, Substance Abuse and Mental Health Services Administration, Office of Applied Studies; Rockville, MD: 2015. National Survey on Drug Use and Health (U.S.), and United States.

8. Hasin DS, et al. Prevalence and Correlates of DSM-5 Cannabis Use Disorder, 2012-2013: Findings from the National Epidemiologic Survey on Alcohol and Related Conditions-III. American Journal of Psychiatry. 2016; 173(6):588-599. [PubMed: 26940807]

9. Khan SS, et al. Gender differences in cannabis use disorders: results from the National Epidemiologic Survey of Alcohol and Related Conditions. Drug Alcohol Depend. 2013; 130(1-3): 101-8. [PubMed: 23182839]

10. Hernandez-Avila CA, Rounsaville BJ, Kranzler HR. Opioid-, cannabis- and alcohol-dependent women show more rapid progression to substance abuse treatment. Drug Alcohol Depend. 2004; 74(3):265-72. [PubMed: 15194204]

11. Cooper ZD, Haney M. Investigation of sex-dependent effects of cannabis in daily cannabis smokers. Drug Alcohol Depend. 2014; 136:85-91. This study importantly examines cannabis abuse-related subjective effects in women and men matched for cannabis use, and reveals greater sensitivity to abuse liability in women compared to men. [PubMed: 24440051]

12. Navarro M, Rodriguez de Fonseca F. The neurobiology of cannabinoid transmission: from anandamide signaling to higher cerebral functions and disease. Neurobiol Dis. 1998; 5(6 Pt B): 379-85. [PubMed: 9974172]

13. Onaivi ES, et al. Endocannabinoids and cannabinoid receptor genetics. Prog Neurobiol. 2002; 66(5):307-44. [PubMed: 12015198]

14. Wegener N, Koch M. Neurobiology and systems physiology of the endocannabinoid system. Pharmacopsychiatry. 2009; (42 Suppl 1):S79-86. [PubMed: 19434559]

15. Elphick MR. The evolution and comparative neurobiology of endocannabinoid signalling. Philos Trans R Soc Lond B Biol Sci. 2012; 367(1607):3201-15. [PubMed: 23108540]

16. Devane WA, et al. Determination and characterization of a cannabinoid receptor in rat brain. Molecular Pharmacology. 1988; 34(5):605. [PubMed: 2848184]

17. Herkenham M, et al. Cannabinoid receptor localization in brain. Proceedings of the National Academy of Sciences. 1990; 87(5):1932-1936.

18. Munro S, Thomas KL, Abu-Shaar M. Molecular characterization of a peripheral receptor for cannabinoids. Nature. 1993; 365(6441):61-5. [PubMed: 7689702]

19. Gong J-P, et al. Cannabinoid CB2 receptors: Immunohistochemical localization in rat brain. Brain Research. 2006; 1071(1):10-23. [PubMed: 16472786]

20. Devane WA, et al. Isolation and Structure of a Brain Constituent That Binds to the Cannabinoid Receptor. Science. 1992; 258(5090):1946-1949. [PubMed: 1470919]

21. Mechoulam R, et al. Identification of an endogenous 2-monoglyceride, present in canine gut, that binds to cannabinoid receptors. Biochemical Pharmacology. 1995; 50(1):83-90. [PubMed: 7605349]

22. Stella N, Schweitzer P, Piomelli D. A second endogenous cannabinoid that modulates long-term potentiation. Nature. 1997; 388(6644):773-778. [PubMed: 9285589]

23. Sugiura T, et al. Evidence That the Cannabinoid CB1 Receptor Is a 2-Arachidonoylglycerol Receptor: STRUCTURE-ACTIVITY RELATIONSHIP OF 2-ARACHIDONOYLGLYCEROL, ETHER-LINKED ANALOGUES, AND RELATED COMPOUNDS. Journal of Biological Chemistry. 1999; 274(5):2794-2801. [PubMed: 9915812]

24. Tai S, Fantegrossi WE. Synthetic Cannabinoids: Pharmacology, Behavioral Effects, and Abuse Potential. Current addiction reports. 2014; 1(2):129-136. [PubMed: 26413452] 
25. Gardner EL. Addictive potential of cannabinoids: the underlying neurobiology. Chem Phys Lipids. 2002; 121(1-2):267-90. [PubMed: 12505706]

26. Fattore L, et al. Neurobiological mechanisms of cannabinoid addiction. Mol Cell Endocrinol. 2008; 286(1-2 Suppl 1):S97-S107. [PubMed: 18372102]

27. Di Chiara G, Imperato A. Drugs abused by humans preferentially increase synaptic dopamine concentrations in the mesolimbic system of freely moving rats. Proc Natl Acad Sci U S A. 1988; 85(14):5274-8. [PubMed: 2899326]

28. Lopez-Moreno JA, et al. The pharmacology of the endocannabinoid system: functional and structural interactions with other neurotransmitter systems and their repercussions in behavioral addiction. Addict Biol. 2008; 13(2):160-87. [PubMed: 18422831]

29. Maldonado R, et al. Neurochemical basis of cannabis addiction. Neuroscience. $2011 ; 181: 1-17$. [PubMed: 21334423]

30. Parsons LH, Hurd YL. Endocannabinoid signalling in reward and addiction. Nature Reviews Neuroscience. 2015

31. Fattore L, Fratta W. How important are sex differences in cannabinoid action? Br J Pharmacol. 2010; 160(3):544-8. [PubMed: 20590564]

32. Gorzalka BB, Hill MN, Chang SC. Male-female differences in the effects of cannabinoids on sexual behavior and gonadal hormone function. Horm Behav. 2010; 58(1):91-9. [PubMed: 19733173]

33. Craft RM, Marusich JA, Wiley JL. Sex differences in cannabinoid pharmacology: a reflection of differences in the endocannabinoid system? Life Sci. 2013; 92(8-9):476-81. [PubMed: 22728714]

34. Gonzalez S, et al. Sex steroid influence on cannabinoid $\mathrm{CB}(1)$ receptor mRNA and endocannabinoid levels in the anterior pituitary gland. Biochem Biophys Res Commun. 2000; 270(1):260-6. [PubMed: 10733937]

35. Xing G, et al. Cannabinoid receptor expression and phosphorylation are differentially regulated between male and female cerebellum and brain stem after repeated stress: Implication for PTSD and drug abuse. Neuroscience Letters. 2011; 502(1):5-9. [PubMed: 21600961]

36. Xing G, et al. Differential Expression of Brain Cannabinoid Receptors between Repeatedly Stressed Males and Females may Play a Role in Age and Gender-Related Difference in Traumatic Brain Injury: Implications from Animal Studies. Front Neurol. 2014; 5:161. [PubMed: 25221540]

37. Rodriguez de Fonseca F, et al. Cannabinoid receptors in rat brain areas: sexual differences, fluctuations during estrous cycle and changes after gonadectomy and sex steroid replacement. Life Sci. 1994; 54(3):159-70. [PubMed: 8289577]

38. Riebe CJ, et al. Estrogenic regulation of limbic cannabinoid receptor binding. Psychoneuroendocrinology. 2010; 35(8):1265-9. [PubMed: 20207489]

39. Reich CG, Taylor ME, McCarthy MM. Differential effects of chronic unpredictable stress on hippocampal CB1 receptors in male and female rats. Behav Brain Res. 2009; 203(2):264-9. [PubMed: 19460405]

40•. Castelli MP, et al. Male and female rats differ in brain cannabinoid CB1 receptor density and function and in behavioural traits predisposing to drug addiction: effect of ovarian hormones. Curr Pharm Des. 2014; 20(13):2100-13. The authors importantly investigate the impact of ovarian hormones on CB1-R density and function, and on various behavioral traits. [PubMed: 23829370]

41. Zamberletti E, et al. Gender-dependent behavioral and biochemical effects of adolescent delta-9tetrahydrocannabinol in adult maternally deprived rats. Neuroscience. 2012; 204:245-57. [PubMed: 22178986]

42. Normandin MD, et al. Imaging the cannabinoid CB1 receptor in humans with [11C]OMAR: assessment of kinetic analysis methods, test-retest reproducibility, and gender differences. $\mathbf{J}$ Cereb Blood Flow Metab. 2015; 35(8):1313-22. The authors of this study use PET imaging to measure CB1-R density in healthy women and men, and reveal widespread lower density in men compared to women. [PubMed: 25833345]

43. Neumeister A, et al. Elevated brain cannabinoid CB1 receptor availability in post-traumatic stress disorder: a positron emission tomography study. Mol Psychiatry. 2013; 18(9):1034-40. [PubMed: 23670490] 
44. Van Laere K, et al. Gender-dependent increases with healthy aging of the human cerebral cannabinoid-type 1 receptor binding using [(18)F]MK-9470 PET. Neuroimage. 2008; 39(4):153341. [PubMed: 18077184]

45. Lex BW, et al. Effects of acute marijuana smoking on pulse rate and mood states in women. Psychopharmacology (Berl). 1984; 84(2):178-87. [PubMed: 6438677]

46. Penetar DM, et al. Transdermal nicotine alters some of marihuana's effects in male and female volunteers. Drug and Alcohol Dependence. 2005; 79(2):211-223. [PubMed: 16002030]

47. Cocchetto DM, et al. Relationship between plasma delta-9-tetrahydrocannabinol concentration and pharmacologic effects in man. Psychopharmacology. 1981; 75(2):158-164. [PubMed: 6275440]

48. Cooper ZD, Haney M. Sex-dependent effects of cannabis-induced analgesia. Drug Alcohol Depend. 2016; 167:112-20. The authors demonstrate greater cannabis-induced analgesia in men, compared to women, and show similar subjective drug effects in both groups. [PubMed: 27522535]

49. Mathew RJ, Wilson WH, Davis R. Postural syncope after marijuana: a transcranial Doppler study of the hemodynamics. Pharmacology Biochemistry and Behavior. 2003; 75(2):309-318.

50. Kaufmann RM, et al. Acute psychotropic effects of oral cannabis extract with a defined content of Delta9-tetrahydrocannabinol (THC) in healthy volunteers. Pharmacopsychiatry. 2010; 43(1):2432. [PubMed: 20178093]

51. Narimatsu S, et al. Sex difference in the oxidative metabolism of delta 9-tetrahydrocannabinol in the rat. Biochem Pharmacol. 1991; 41(8):1187-94. [PubMed: 1848985]

52. Tseng AH, Harding JW, Craft RM. Pharmacokinetic factors in sex differences in Delta 9tetrahydrocannabinol-induced behavioral effects in rats. Behav Brain Res. 2004; 154(1):77-83. [PubMed: 15302113]

53. Wiley JL, Burston JJ. Sex differences in Delta(9)-tetrahydrocannabinol metabolism and in vivo pharmacology following acute and repeated dosing in adolescent rats. Neurosci Lett. 2014; 576:51-5. This study importantly demonstrates THC metabolism differences between female and male rats. [PubMed: 24909619]

54. Klumpers LE, et al. Manipulating brain connectivity with $\delta 9$-tetrahydrocannabinol: A pharmacological resting state FMRI study. NeuroImage. 2012; 63(3):1701-1711. [PubMed: 22885247]

55. Jones AW, Holmgren A, Kugelberg FC. Driving under the influence of cannabis: a 10-year study of age and gender differences in the concentrations of tetrahydrocannabinol in blood. Addiction. 2008; 103(3):452-61. [PubMed: 18190663]

56•. Hurd YL, et al. Trajectory of adolescent cannabis use on addiction vulnerability. Neuropharmacology. 2014; 76:416-424. This review details the unique vulnerability to cannabis abuse with cannabis exposure during adolescence, focusing on the endocannabinoid system as well as genetic and behavioral traits that may render individuals more vulnerable to addiction. [PubMed: 23954491]

57. Levine A, et al. Evidence for the Risks and Consequences of Adolescent Cannabis Exposure. Journal of the American Academy of Child \& Adolescent Psychiatry. 2017; 56(3):214-225. [PubMed: 28219487]

58. Viveros MP, et al. The endocannabinoid system in critical neurodevelopmental periods: sex differences and neuropsychiatric implications. J Psychopharmacol. 2012; 26(1):164-76. [PubMed: 21669929]

59. Viveros MP, et al. Framework for sex differences in adolescent neurobiology: a focus on cannabinoids. Neurosci Biobehav Rev. 2011; 35(8):1740-51. [PubMed: 20869396]

60•. Rubino T, Parolaro D. Sex-dependent vulnerability to cannabis abuse in adolescence. Front Psychiatry. 2015; 6:56. The authors of this paper comprehensively review preclinical, and some clinical, studies investigating vulnerability to cannabis abuse during adolescence, and how this differs in females compared to males. [PubMed: 25941498]

61. Rubino T, et al. Chronic delta 9-tetrahydrocannabinol during adolescence provokes sex-dependent changes in the emotional profile in adult rats: behavioral and biochemical correlates. Neuropsychopharmacology. 2008; 33(11):2760-71. [PubMed: 18172430] 
62. Burston JJ, et al. Regional enhancement of cannabinoid $\mathrm{CB}_{1}$ receptor desensitization in female adolescent rats following repeated Delta-tetrahydrocannabinol exposure. Br J Pharmacol. 2010; 161(1):103-12. [PubMed: 20718743]

63. Silva L, et al. Sex-specific alterations in hippocampal cannabinoid 1 receptor expression following adolescent delta-9-tetrahydrocannabinol treatment in the rat. Neurosci Lett. 2015; 602:89-94. The authors demonstrate sex-specific downregulation of CB1-R expression in rats exposed to THC in adolescence, specifically more persistent downregulation in females compared to males. [PubMed: 26118897]

64- Weed PF, et al. Chronic Delta9-Tetrahydrocannabinol during Adolescence Differentially Modulates Striatal CB1 Receptor Expression and the Acute and Chronic Effects on Learning in Adult Rats. J Pharmacol Exp Ther. 2016; 356(1):20-31. This study reveals hippocampal enhancement in CB1-R density in adult females, specifically, and in striatum in females and males, after chronic THC exposure during adolescence. [PubMed: 26462539]

65. Winsauer PJ, et al. Long-term behavioral and pharmacodynamic effects of delta-9tetrahydrocannabinol in female rats depend on ovarian hormone status. Addiction Biology. 2011; 16(1):64-81. [PubMed: 21158010]

66. Lopez-Gallardo M, et al. Maternal deprivation and adolescent cannabinoid exposure impact hippocampal astrocytes, CB1 receptors and brain-derived neurotrophic factor in a sexually dimorphic fashion. Neuroscience. 2012; 204:90-103. [PubMed: 22001306]

67. Winsauer PJ, et al. Ovarian hormones and chronic administration during adolescence modify the discriminative stimulus effects of delta-9-tetrahydrocannabinol ( $\triangle 9$-THC) in adult female rats. Pharmacology Biochemistry and Behavior. 2012; 102(3):442-449.

68. Higuera-Matas A, et al. Sex-specific disturbances of the glutamate/GABA balance in the hippocampus of adult rats subjected to adolescent cannabinoid exposure. Neuropharmacology. 2012; 62(5-6):1975-84. [PubMed: 22245681]

69- Zamberletti E, et al. Long-term hippocampal glutamate synapse and astrocyte dysfunctions underlying the altered phenotype induced by adolescent THC treatment in male rats. Pharmacol Res. 2016; 111:459-70. The authors of this study provide data from male rats comparable to data obtained from their earlier study of adolescent cannabis exposure effects on adult female rats, and show male-specific changes in hippocampus compared to female-specific changes in prefrontal cortex. [PubMed: 27422357]

70. Higuera-Matas A, et al. Periadolescent exposure to cannabinoids alters the striatal and hippocampal dopaminergic system in the adult rat brain. European Neuropsychopharmacology. 2010; 20(12):895-906. [PubMed: 20655181]

71. Volkow ND, et al. Decreased dopamine brain reactivity in marijuana abusers is associated with negative emotionality and addiction severity. Proc Natl Acad Sci U S A. 2014; 111(30):E3149-56. [PubMed: 25024177]

72. Albrecht DS, et al. Striatal $\mathrm{D}(2) / \mathrm{D}(3)$ receptor availability is inversely correlated with cannabis consumption in chronic marijuana users. Drug Alcohol Depend. 2013; 128(1-2):52-7. [PubMed: 22909787]

73•. van de Giessen E, et al. Deficits in striatal dopamine release in cannabis dependence. Mol Psychiatry. 2017; 22(1):68-75. The authors of this study show lower dopamine release in cannabis-dependent subjects compared to healthy controls, and investigate the correlation between dopamine release and a variety of behavioral and cognitive measures. [PubMed: 27001613]

74. Carroll, ME., Meisch, RA. Acquisition of Drug Self-Administration. In: Olmstead, MC., editor. Animal Models of Drug Addiction. Humana Press; Totowa, NJ: 2011. p. 237-265.

75. Justinova Z, et al. Self-administration of cannabinoids by experimental animals and human marijuana smokers. Pharmacology Biochemistry and Behavior. 2005; 81(2):285-299.

76•. Tanda G. Preclinical studies on the reinforcing effects of cannabinoids. A tribute to the scientific research of Dr. Steve Goldberg. Psychopharmacology (Berl). 2016; 233(10):1845-66. This review focuses on preclinical literature which examines the reinforcing effects of cannabinoids with techniques such as cannabinoid discrimination, intracranial self-stimulation, conditioned place preference, and self-administration. [PubMed: 27026633] 
77. Scherma M, et al. Adolescent Delta(9)-Tetrahydrocannabinol Exposure Alters WIN55,212-2 SelfAdministration in Adult Rats. Neuropsychopharmacology. 2016; 41(5):1416-26. [PubMed: 26388146]

78. Jacobus J, et al. Functional consequences of marijuana use in adolescents. Pharmacology Biochemistry and Behavior. 2009; 92(4):559-565.

79. Batalla A, et al. Structural and Functional Imaging Studies in Chronic Cannabis Users: A Systematic Review of Adolescent and Adult Findings. PLOS ONE. 2013; 8(2):e55821. [PubMed: 23390554]

80. Gruber SA, et al. Worth the wait: effects of age of onset of marijuana use on white matter and impulsivity. Psychopharmacology. 2014; 231(8):1455-1465. [PubMed: 24190588]

81. Yucel M, et al. White-matter abnormalities in adolescents with long-term inhalant and cannabis use: a diffusion magnetic resonance imaging study. J Psychiatry Neurosci. 2010; 35(6):409-12. [PubMed: 20731960]

82. Jacobus J, et al. Cortical thickness in adolescent marijuana and alcohol users: A three-year prospective study from adolescence to young adulthood. Developmental Cognitive Neuroscience. 2015; 16:101-109. [PubMed: 25953106]

83. McQueeny T, et al. Gender effects on amygdala morphometry in adolescent marijuana users. Behav Brain Res. 2011; 224(1):128-34. [PubMed: 21664935]

84. Price JS, et al. Effects of marijuana use on prefrontal and parietal volumes and cognition in emerging adults. Psychopharmacology (Berl). 2015; 232(16):2939-50. [PubMed: 25921032]

85. Boulos PK, et al. Brain Cortical Thickness Differences in Adolescent Females with Substance Use Disorders. PLOS ONE. 2016; 11(4):e0152983. [PubMed: 27049765]

86. Chumachenko SY, et al. Brain cortical thickness in male adolescents with serious substance use and conduct problems. The American Journal of Drug and Alcohol Abuse. 2015; 41(5):414-424. [PubMed: 26337200]

87. Dalwani M, et al. Reduced cortical gray matter volume in male adolescents with substance and conduct problems. Drug and Alcohol Dependence. 2011; 118(2-3):295-305. [PubMed: 21592680]

88. Dalwani MS, et al. Female Adolescents with Severe Substance and Conduct Problems Have Substantially Less Brain Gray Matter Volume. PLOS ONE. 2015; 10(5):e0126368. [PubMed: 26000879]

89. Wilson W, et al. Brain Morphological Changes and Early Marijuana Use. Journal of Addictive Diseases. 2000; 19(1):1-22.

90. Wetherill RR, et al. Early Versus Late Onset of Cannabis Use: Differences in Striatal Response to Cannabis Cues. Cannabis and Cannabinoid Research. 2016; 1(1):229-233. [PubMed: 28331903]

91. Cheetham A, et al. Orbitofrontal volumes in early adolescence predict initiation of cannabis use: a 4-year longitudinal and prospective study. Biol Psychiatry. 2012; 71(8):684-92. [PubMed: 22129756]

92. Mansbach R, et al. Failure of [DELTA] 9-tetrahydrocannabinol and CP 55,940 to maintain intravenous self-administration under a fixed-interval schedule in rhesus monkeys. Behavioural pharmacology. 1994; 5(2):219. [PubMed: 11224271]

93. Lefever TW, et al. Evaluation of WIN 55,212-2 self-administration in rats as a potential cannabinoid abuse liability model. Pharmacology Biochemistry and Behavior. 2014; 118:30-35.

94. John WS, Martin TJ, Nader MA. Behavioral Determinants of Cannabinoid Self-Administration in Old World Monkeys. Neuropsychopharmacology. 2017; 42(7):1522-1530. [PubMed: 28059083]

95. Fadda $P$, et al. Cannabinoid self-administration increases dopamine release in the nucleus accumbens. Neuroreport. 2006; 17(15):1629-32. [PubMed: 17001282]

96. Lecca D, et al. Monitoring extracellular dopamine in the rat nucleus accumbens shell and core during acquisition and maintenance of intravenous WIN 55,212-2 self-administration. Psychopharmacology (Berl). 2006; 188(1):63-74. [PubMed: 16850116]

97. De Luca MA, et al. Endocannabinoid 2-Arachidonoylglycerol Self-Administration by SpragueDawley Rats and Stimulation of in vivo Dopamine Transmission in the Nucleus Accumbens Shell. Front Psychiatry. 2014; 5:140. [PubMed: 25368584] 
98. Tanda G, Munzar P, Goldberg SR. Self-administration behavior is maintained by the psychoactive ingredient of marijuana in squirrel monkeys. Nat Neurosci. 2000; 3(11):1073-1074. [PubMed: 11036260]

99. Braida D, et al. Intracerebral self-administration of the cannabinoid receptor agonist CP 55,940 in the rat: interaction with the opioid system. European Journal of Pharmacology. 2001; 413(2-3): 227-234. [PubMed: 11226397]

100. Navarro M, et al. Functional interaction between opioid and cannabinoid receptors in drug selfadministration. J Neurosci. 2001; 21(14):5344-50. [PubMed: 11438610]

101. Braida D, et al. $\Delta 9$-Tetrahydrocannabinol-induced conditioned place preference and intracerebroventricular self-administration in rats. European Journal of Pharmacology. 2004; 506(1):63-69. [PubMed: 15588625]

102. Justinova $Z$, et al. The opioid antagonist naltrexone reduces the reinforcing effects of Delta 9 tetrahydrocannabinol (THC) in squirrel monkeys. Psychopharmacology (Berl). 2004; 173(1-2): 186-94. [PubMed: 14668977]

103. Mendizabal V, Zimmer A, Maldonado R. Involvement of kappa/dynorphin system in WIN 55,212-2 self-administration in mice. Neuropsychopharmacology. 2006; 31(9):1957-66. [PubMed: 16292318]

104. Justinova Z, et al. Reinforcing and neurochemical effects of cannabinoid CB1 receptor agonists, but not cocaine, are altered by an adenosine A2A receptor antagonist. Addict Biol. 2011; 16(3): 405-15. [PubMed: 21054689]

105. Justinova Z, et al. Differential effects of presynaptic versus postsynaptic adenosine A2A receptor blockade on Delta9-tetrahydrocannabinol (THC) self-administration in squirrel monkeys. J Neurosci. 2014; 34(19):6480-4. [PubMed: 24806674]

106. Struik D, et al. The anabolic steroid nandrolone alters cannabinoid self-administration and brain CB1 receptor density and function. Pharmacol Res. 2017; 115:209-217. [PubMed: 27890818]

107. Roth ME, Cosgrove KP, Carroll ME. Sex differences in the vulnerability to drug abuse: a review of preclinical studies. Neuroscience \& Biobehavioral Reviews. 2004; 28(6):533-546. [PubMed: 15527861]

108. Fattore L, et al. Cannabinoid self-administration in rats: sex differences and the influence of ovarian function. Br J Pharmacol. 2007; 152(5):795-804. [PubMed: 17891164]

109. Hempel BJ, et al. An assessment of sex differences in $\Delta 9$-tetrahydrocannabinol (THC) taste and place conditioning. Pharmacology Biochemistry and Behavior. 2017; 153:69-75.

110. Wiley JL, et al. Comparison of the discriminative stimulus and response rate effects of Delta9tetrahydrocannabinol and synthetic cannabinoids in female and male rats. Drug Alcohol Depend. 2017; 172:51-59. This study innovatively compares THC discrimination directly between female and male rats, and reveals female-specific enhanced sensitivity to THC effects compared to males. [PubMed: 28130989]

111. Haney M. Self-administration of cocaine, cannabis and heroin in the human laboratory: benefits and pitfalls. Addict Biol. 2009; 14(1):9-21. [PubMed: 18855806]

112. Hart CL, et al. Reinforcing effects of oral Delta9-THC in male marijuana smokers in a laboratory choice procedure. Psychopharmacology (Berl). 2005; 181(2):237-43. [PubMed: 15830233]

113. Cappell H, Pliner P. Regulation of the self-administration of marihuana by psychological and pharmacological variables. Psychopharmacologia. 1974; 40(1):65-76. [PubMed: 4445447]

114. Kelly TH, et al. Effects of delta 9-tetrahydrocannabinol and social context on marijuana selfadministration by humans. Pharmacol Biochem Behav. 1994; 49(3):763-8. [PubMed: 7862735]

115. Babor TF, et al. Marijuana, affect and tolerance: a study of subchronic self-administration in women. NIDA Res Monogr. 1984; 49:199-204. [PubMed: 6434960]

116. Mello NK, Mendelson JH. Operant acquisition of marihuana by women. J Pharmacol Exp Ther. 1985; 235(1):162-71. [PubMed: 2995644]

117. Griffin ML, et al. Marihuana use across the menstrual cycle. Drug and Alcohol Dependence. 1986; 18(2):213-224. [PubMed: 3780416]

118. Chait LD, Zacny JP. Reinforcing and subjective effects of oral delta 9-THC and smoked marijuana in humans. Psychopharmacology (Berl). 1992; 107(2-3):255-62. [PubMed: 1319601] 
119. Hart CL, et al. Effects of oral THC maintenance on smoked marijuana self-administration. Drug Alcohol Depend. 2002; 67(3):301-9. [PubMed: 12127201]

120. Haney M, et al. Oral Cannabidiol does not Alter the Subjective, Reinforcing or Cardiovascular Effects of Smoked Cannabis. Neuropsychopharmacology. 2016; 41(8):1974-82. [PubMed: 26708108]

121 . Haney M, et al. Naltrexone Maintenance Decreases Cannabis Self-Administration and Subjective Effects in Daily Cannabis Smokers. Neuropsychopharmacology. 2015; 40(11):2489-98. This study highlights the treatment potential of the opioid antagonist naltrexone in reducing cannabis use, in nontreatment-seeking daily cannabis smokers. [PubMed: 25881117]

122. Wardle MC, Marcus BA, de Wit H. A Preliminary Investigation of Individual Differences in Subjective Responses to D-Amphetamine, Alcohol, and Delta-9-Tetrahydrocannabinol Using a Within-Subjects Randomized Trial. PLOS ONE. 2015; 10(10):e0140501. [PubMed: 26513587]

123. Haney M. Opioid Antagonism of Cannabinoid Effects: Differences between Marijuana Smokers and Nonmarijuana Smokers. Neuropsychopharmacology. 2006; 32(6):1391-1403. [PubMed: 17091128]

124• Henry EA, et al. Cannabis cue reactivity and craving among never, infrequent and heavy cannabis users. Neuropsychopharmacology. 2014; 39(5):1214-21. The authors of this study uniquely record event-related brain potentials from cannabis users exposed to cannabis cues, and reveal significant gender differences in the results. [PubMed: 24264815]

125•. Wetherill RR, et al. Sex differences in associations between cannabis craving and neural responses to cannabis cues: Implications for treatment. Exp Clin Psychopharmacol. 2015; 23(4): 238-46. This study shows gender-dependent differences in the correlation between cannabis craving and subliminally presented cannabis cue-induced neural activation, in a population of cannabis-dependent, treatment-seeking adults. [PubMed: 26237321]

126. Haughey HM, et al. Marijuana withdrawal and craving: influence of the cannabinoid receptor 1 (CNR1) and fatty acid amide hydrolase (FAAH) genes. Addiction. 2008; 103(10):1678-1686. [PubMed: 18705688]

127. Filbey FM, et al. Individual and Additive Effects of the CNR1 and FAAH Genes on Brain Response to Marijuana Cues. Neuropsychopharmacology. 2009; 35(4):967-975. [PubMed: 20010552]

128. Lundahl LH, Johanson CE. Cue-induced craving for marijuana in cannabis-dependent adults. Exp Clin Psychopharmacol. 2011; 19(3):224-30. [PubMed: 21480734]

129. Charboneau EJ, et al. Cannabis cue-induced brain activation correlates with drug craving in limbic and visual salience regions: preliminary results. Psychiatry Res. 2013; 214(2):122-31. [PubMed: 24035535]

130•. Lorenzetti V, Solowij N, Yücel M. The Role of Cannabinoids in Neuroanatomic Alterations in Cannabis Users. Biological Psychiatry. 2016; 79(7):e17-e31. This review highlights structural neuroimaging studies in cannabis use effects on the brain, with a focus on evidence from regions including hippocampus, prefrontal cortex, amygdala, and cerebellum. [PubMed: 26858212]

131•. Weinstein A, Livny A, Weizman A. Brain imaging studies on the cognitive, pharmacological and neurobiological effects of cannabis in humans: evidence from studies of adult users. Current pharmaceutical design. 2016; 22(42):6366-6379. The authors comprehensively review brain imaging studies in humans that investigate the cognitive, neurobiological, and pharmacological effects of cannabis exposure. [PubMed: 27549374]

132• Ketcherside A, Baine J, Filbey F. Sex Effects of Marijuana on Brain Structure and Function. Curr Addict Rep. 2016; 3:323-331. This is a comprehensive review of gender differences in the effects of cannabis on brain structure and function, with a focus on human studies. [PubMed: 27525213]

133. Cousijn J, et al. Grey matter alterations associated with cannabis use: Results of a VBM study in heavy cannabis users and healthy controls. NeuroImage. 2012; 59(4):3845-3851. [PubMed: 21982932]

134. Wetherill RR, et al. Cannabis, Cigarettes, and Their Co-Occurring Use: Disentangling Differences in Gray Matter Volume. International Journal of Neuropsychopharmacology. 2015; 18(10):pyv061-pyv061. [PubMed: 26045474] 
135. Block RI, et al. Effects of frequent marijuana use on brain tissue volume and composition. Neuroreport. 2000; 11(3):491-496. [PubMed: 10718301]

136•. Chye $\mathrm{Y}$, et al. Orbitofrontal and caudate volumes in cannabis users: a multi-site mega-analysis comparing dependent versus non-dependent users. Psychopharmacology. 2017:1-11. The authors incorporate data from multiple neuroimaging sites to investigate structural brain differences in dependent cannabis users compared to non-dependent users, and additionally demonstrate gender differences in these findings.

137. Jager G, et al. Effects of frequent cannabis use on hippocampal activity during an associative memory task. European Neuropsychopharmacology. 2007; 17(4):289-297. [PubMed: 17137758]

138• Tomasi D, Wang GJ, Volkow ND. Balanced modulation of striatal activation from D2 /D3 receptors in caudate and ventral striatum: Disruption in cannabis abusers. Hum Brain Mapp. 2015; 36(8):3154-66. This study utilizes fMRI and PET imaging modalities to investigate modulation of striatal activity from dopamine D2/D3 receptors in cannabis-using subjects. [PubMed: 26058801]

139. Skosnik PD, et al. The effect of cannabis use and gender on the visual steady state evoked potential. Clin Neurophysiol. 2006; 117(1):144-56. [PubMed: 16364685]

140•. Wiers CE, et al. Cannabis Abusers Show Hypofrontality and Blunted Brain Responses to a Stimulant Challenge in Females but not in Males. Neuropsychopharmacology. 2016; 41(10): 2596-605. This study investigates baseline and methylphenidate-induced glucose metabolism in cannabis abusers compared to healthy controls, and reveals significant gender effects in the findings. [PubMed: 27156854]

141. Muetzel RL, et al. In vivo $1 \mathrm{H}$ magnetic resonance spectroscopy in young-adult daily marijuana users. NeuroImage: Clinical. 2013; 2:581-589. [PubMed: 23956957]

142. Cuttler C, Mischley LK, Sexton M. Sex Differences in Cannabis Use and Effects: A CrossSectional Survey of Cannabis Users. Cannabis and Cannabinoid Research. 2016; 1(1):166-175. [PubMed: 28861492]

143•. Foster KT, et al. Gender Differences in Internalizing Symptoms and Suicide Risk Among Men and Women Seeking Treatment for Cannabis Use Disorder from Late Adolescence to Middle Adulthood. J Subst Abuse Treat. 2016; 66:16-22. The authors in this study explore the prevalence of internalizing distress and suicide risk in women and men seeking CUD treatment, and suggest higher rates in women compared to men. [PubMed: 27211992]

144. Buckner JD, et al. Peer influence and gender differences in problematic cannabis use among individuals with social anxiety. J Anxiety Disord. 2006; 20(8):1087-102. [PubMed: 16621436]

145. Buckner JD, Zvolensky MJ, Schmidt NB. Cannabis-related impairment and social anxiety: the roles of gender and cannabis use motives. Addict Behav. 2012; 37(11):1294-7. [PubMed: 22766487]

146. Mateos B, et al. Adolescent exposure to nicotine and/or the cannabinoid agonist CP 55,940 induces gender-dependent long-lasting memory impairments and changes in brain nicotinic and CB(1) cannabinoid receptors. J Psychopharmacol. 2011; 25(12):1676-90. [PubMed: 20562169]

147. O'Shea M, McGregor IS, Mallet PE. Repeated cannabinoid exposure during perinatal, adolescent or early adult ages produces similar longlasting deficits in object recognition and reduced social interaction in rats. Journal of Psychopharmacology. 2006; 20(5):611-621. [PubMed: 16714325]

148. Harte-Hargrove LC, Dow-Edwards DL. Withdrawal from THC during adolescence: sex differences in locomotor activity and anxiety. Behav Brain Res. 2012; 231(1):48-59. [PubMed: 22421367]

149•. Silva L, et al. Sex and age specific effects of delta-9-tetrahydrocannabinol during the periadolescent period in the rat: The unique susceptibility of the prepubescent animal. Neurotoxicol Teratol. 2016; 58:88-100. This study comprehensively examines effects of THC exposure before and during puberty, in female and male rats, including effects on CB1-R properties and behavior related to anxiety, depression, and psychosis. [PubMed: 26898326]

150. Biscaia M, et al. Chronic treatment with CP 55,940 during the peri-adolescent period differentially affects the behavioural responses of male and female rats in adulthood. Psychopharmacology (Berl). 2003; 170(3):301-8. [PubMed: 12955302] 
151. O'Shea M, et al. Chronic cannabinoid exposure produces lasting memory impairment and increased anxiety in adolescent but not adult rats. Journal of Psychopharmacology. 2004; 18(4): 502-508. [PubMed: 15582916]

152. Bowers ME, Ressler KJ. Sex-dependence of anxiety-like behavior in cannabinoid receptor 1 (Cnr1) knockout mice. Behav Brain Res. 2016; 300:65-9. [PubMed: 26684509]

153. Terzian AL, Micale V, Wotjak CT. Cannabinoid receptor type 1 receptors on GABAergic vs. glutamatergic neurons differentially gate sex-dependent social interest in mice. Eur J Neurosci. 2014; 40(1):2293-8. [PubMed: 24698342]

154. Rey JM, et al. Mental health of teenagers who use cannabis. The British Journal of Psychiatry. 2002; 180(3):216. [PubMed: 11872513]

155. Patton GC, et al. Cannabis use and mental health in young people: cohort study. BMJ. 2002; 325(7374):1195. [PubMed: 12446533]

156•. Crane NA, Langenecker SA, Mermelstein RJ. Gender differences in the associations among marijuana use, cigarette use, and symptoms of depression during adolescence and young adulthood. Addict Behav. 2015; 49:33-9. The authors of this longitudinal study explore symptoms of depression in cannabis and tobacco using subjects, and suggest that depressive symptoms are related to cannabis use in males, but not females. [PubMed: 26036667]

157. Poulin C, et al. Gender differences in the association between substance use and elevated depressive symptoms in a general adolescent population. Addiction. 2005; 100(4):525-35. [PubMed: 15784067]

158. Harder VS, Stuart EA, Anthony JC. Adolescent cannabis problems and young adult depression: male-female stratified propensity score analyses. Am J Epidemiol. 2008; 168(6):592-601. [PubMed: 18687663]

159. Patton GC, et al. Adolescent suicidal behaviours: a population-based study of risk. Psychological medicine. 1997; 27(03):715-724. [PubMed: 9153691]

160 . Shalit N, et al. The association between cannabis use and suicidality among men and women: A population-based longitudinal study. J Affect Disord. 2016; 205:216-224. This study investigates the correlation of multiple facets of suicidality with cannabis use, in women and men. [PubMed: 27449554]

161. Zilberman ML, et al. The impact of gender, depression, and personality on cravings. Journal of addictive diseases. 2007; 26(1):79-84.

162•. Lundahl LH, Greenwald MK. Effect of oral THC pretreatment on marijuana cue-induced responses in cannabis dependent volunteers. Drug Alcohol Depend. 2015; 149:187-93. This study investigates the potential of oral THC to attenuate cannabis craving, and interestingly reveals that males report feeling more "down" after cannabis cue exposure compared to females. [PubMed: 25725933]

163. Medina KL, et al. Depressive symptoms in adolescents: associations with white matter volume and marijuana use. Journal of Child Psychology and Psychiatry. 2007; 48(6):592-600. [PubMed: 17537075]

164. Zamberletti E, et al. Cortical neuroinflammation contributes to long-term cognitive dysfunctions following adolescent delta-9-tetrahydrocannabinol treatment in female rats. Eur Neuropsychopharmacol. 2015; 25(12):2404-15. This study comprehensively examines molecular and behavioral effects of THC exposure during adolescence on adult female rats, with a focus on neuroinflammation and affective behavior. [PubMed: 26499171]

165. Morrish AC, et al. Protracted cannabinoid administration elicits antidepressant behavioral responses in rats: role of gender and noradrenergic transmission. Physiol Behav. 2009; 98(1-2): 118-24. [PubMed: 19414024]

166. D'Souza DC, et al. The psychotomimetic effects of intravenous delta-9-tetrahydrocannabinol in healthy individuals: implications for psychosis. Neuropsychopharmacology. 2004; 29(8):1558. [PubMed: 15173844]

167. Decoster J, et al. Age at onset of psychotic disorder: cannabis, BDNF Val66Met, and sex-specific models of gene-environment interaction. Am J Med Genet B Neuropsychiatr Genet. 2011; 156B(3):363-9. [PubMed: 21305693] 
168. Dekker N, et al. Age at onset of non-affective psychosis in relation to cannabis use, other drug use and gender. Psychol Med. 2012; 42(9):1903-11. [PubMed: 22452790]

169•. Donoghue K, et al. Cannabis use, gender and age of onset of schizophrenia: data from the AESOP study. Psychiatry Res. 2014; 215(3):528-32. This study contributes to a growing body of literature suggesting that gender influences the relationship between cannabis use and age of onset of schizophrenia. [PubMed: 24461684]

170 . Nunez C, et al. Differential effects of sex on substance use between first episode psychosis patients and healthy people. Compr Psychiatry. 2016; 69:169-78. The authors investigate sex differences in cannabis use among patient with first episode psychosis, and demonstrate men smoke cannabis more frequently than women. [PubMed: 27423358]

171. Allegri F, et al. Current cannabis use and age of psychosis onset: a gender-mediated relationship? Results from an 8-year FEP incidence study in Bologna. Psychiatry Res. 2013; 210(1):368-70. [PubMed: 23919899]

172•. Mané A, et al. Cannabis use, COMT, BDNF and age at first-episode psychosis. Psychiatry Research. 2017; 250:38-43. The authors of this study examine the interaction of genetic polymorphisms with cannabis use and the influence of this interaction on age of first episode of psychosis, and additionally examine how gender impacts this relationship. [PubMed: 28142064]

173. Smith MJ, et al. Cannabis-Related Working Memory Deficits and Associated Subcortical Morphological Differences in Healthy Individuals and Schizophrenia Subjects. Schizophrenia Bulletin. 2014; 40(2):287-299. [PubMed: 24342821]

174. Szeszko PR, et al. Anterior cingulate grey-matter deficits and cannabis use in first-episode schizophrenia. The British Journal of Psychiatry. 2007; 190(3):230-236. [PubMed: 17329743]

175. Bangalore SS, et al. Cannabis use and brain structural alterations in first episode schizophrenia A region of interest, voxel based morphometric study. Schizophrenia Research. 2008; 99(1-3):16. [PubMed: 18248793]

176. Rais M, et al. Excessive brain volume loss over time in cannabis-using first-episode schizophrenia patients. American Journal of Psychiatry. 2008; 165(4):490-496. [PubMed: 18281413]

177. James A, et al. Greater white and grey matter changes associated with early cannabis use in adolescent-onset schizophrenia (AOS). Schizophrenia Research. 2011; 128(1-3):91-97. [PubMed: 21388791]

178. Llorente-Berzal A, et al. Sex-dependent effects of maternal deprivation and adolescent cannabinoid treatment on adult rat behaviour. Addict Biol. 2011; 16(4):624-37. [PubMed: 21521421]

179•. Marusich JA, et al. Evaluation of sex differences in cannabinoid dependence. Drug Alcohol Depend. 2014; 137:20-8. This study innovatively examines THC dependence in female and male adult rats, using CB1-R antagonist rimonabant. [PubMed: 24582909]

Curr Addict Rep. Author manuscript; available in PMC 2018 December 01. 


\section{Table 1}

Key Terms and Definitions Used in Text

\begin{tabular}{ll}
\hline Term & Definition \\
\hline Cannabis & $\begin{array}{l}\text { The inhaled or ingested substance commonly known as marijuana; derived from plant in Cannabis genus (species sativa is } \\
\text { common in recreational use and in research studies) }\end{array}$ \\
Cannabinoid & Exogenous CB1-R agonist; examples include THC and synthetic agonists WIN 55,212-2, CP 55,940, and HU-210 \\
CB1-R & Cannabinoid receptor type 1; present throughout human and rodent brains \\
Endocannabinoid & Endogenous CB1-R agonist; examples include $N$-arachidonoylethanolamine (AEA) and 2-arachodonylglycerol (2-AG) \\
Gender & Descriptive term used in analysis of differences between women and men in clinical studies \\
Ovariectomy & Surgical removal of ovaries in rodents; used to examine the role of female sex hormones in cannabinoid biology \\
Sex & Descriptive term used in analysis of differences between females and males in preclinical studies \\
THC & $\Delta^{9}$-tetrahydrocannabinol; the primary psychoactive ingredient in cannabis \\
\hline
\end{tabular}

Curr Addict Rep. Author manuscript; available in PMC 2018 December 01. 


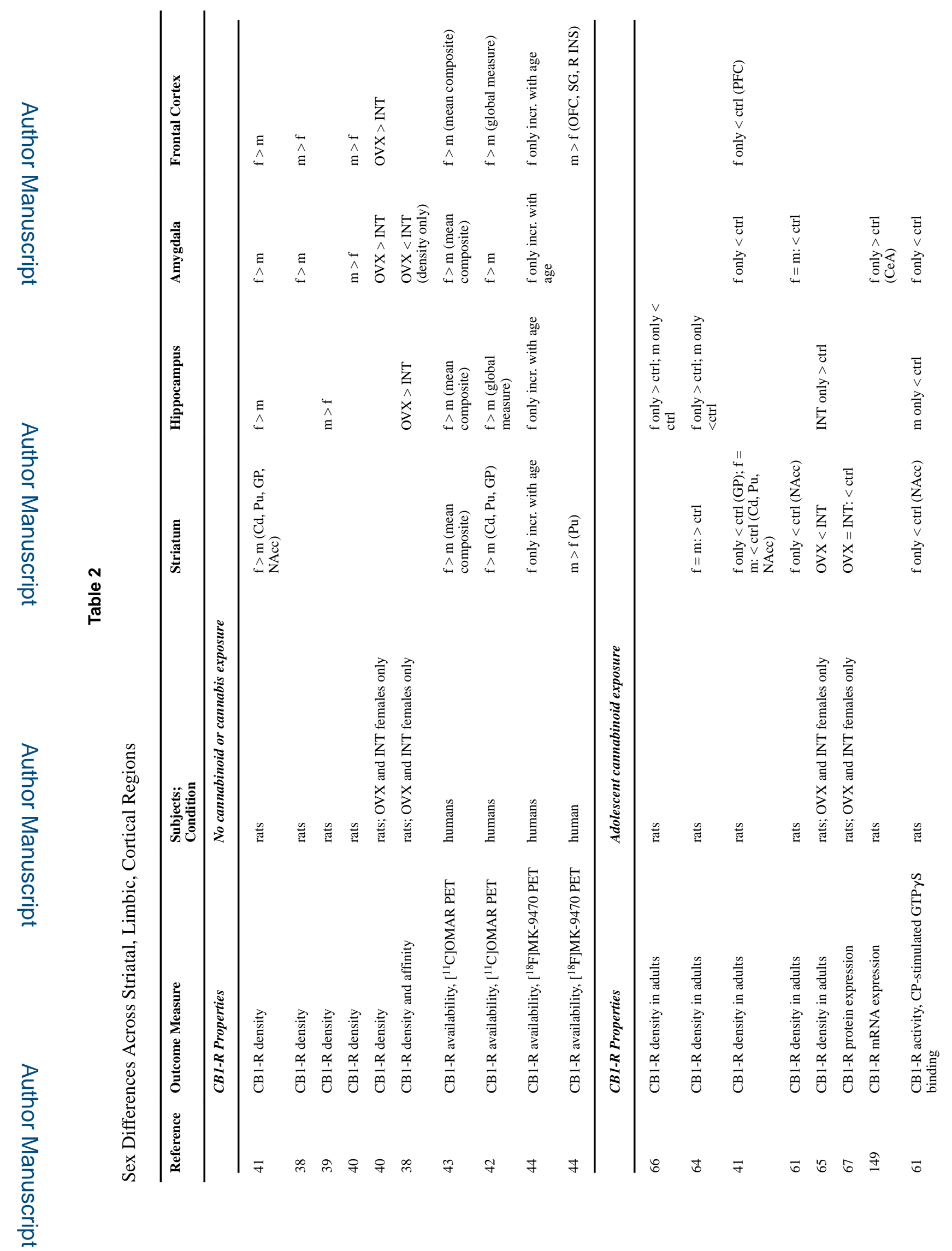

Curr Addict Rep. Author manuscript; available in PMC 2018 December 01. 


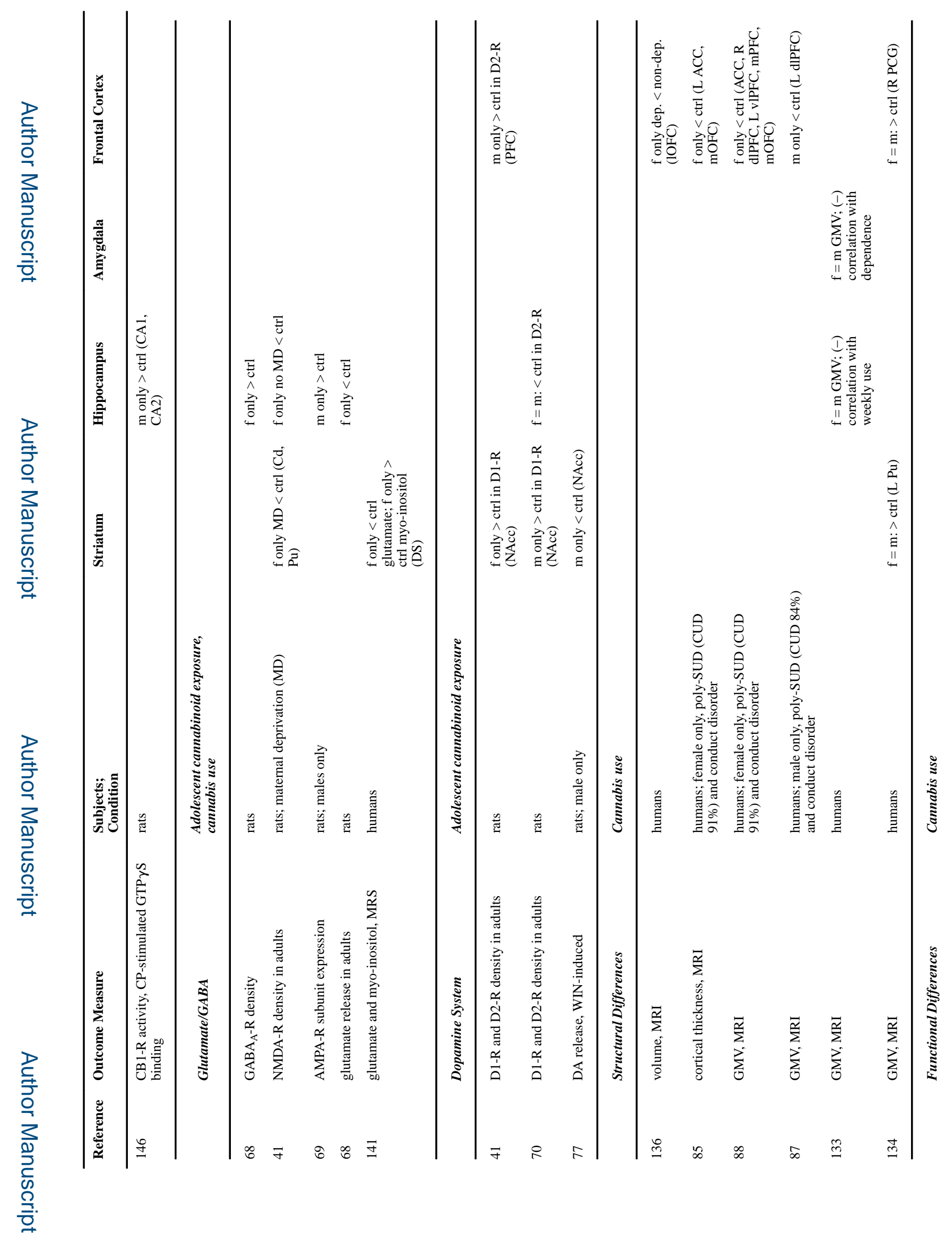

Curr Addict Rep. Author manuscript; available in PMC 2018 December 01. 
Calakos et al.

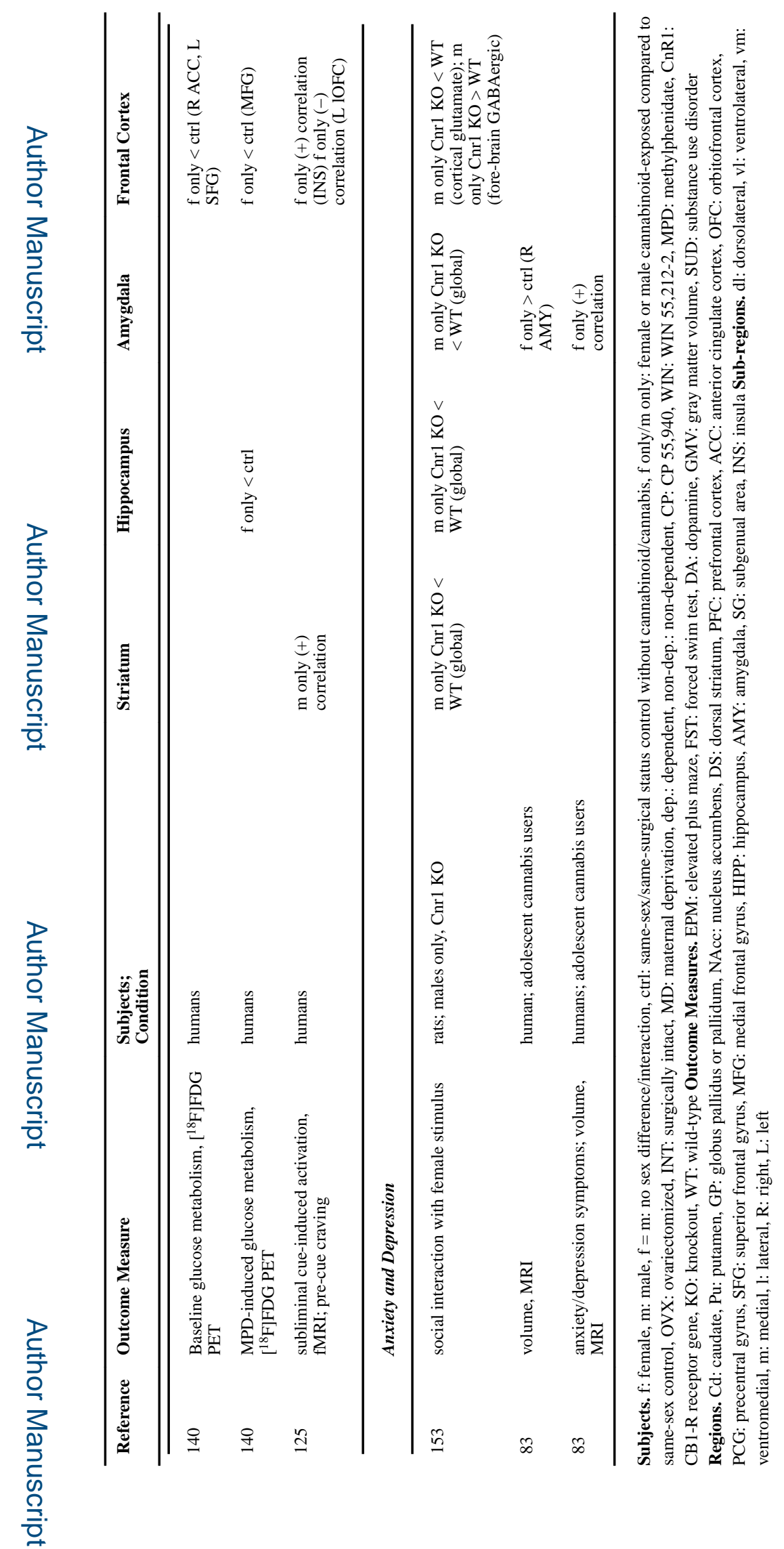

Curr Addict Rep. Author manuscript; available in PMC 2018 December 01. 